\title{
Reversible hippocampal lesions disrupt water maze performance during both recent and remote memory tests
}

\author{
Nicola J. Broadbent, ${ }^{2}$ Larry R. Squire, ${ }^{1,2,3,4}$ and Robert E. Clark ${ }^{1,2,5}$ \\ ${ }^{1}$ Veterans Affairs Medical Center, San Diego, California, 92161, USA; ${ }^{2}$ Department of Psychiatry, ${ }^{3}$ Department of Neurosciences, \\ and ${ }^{4}$ Department of Psychology, University of California, San Diego, California, 92093, USA
}

\begin{abstract}
Conventional lesion methods have shown that damage to the rodent hippocampus can impair previously acquired spatial memory in tasks such as the water maze. In contrast, work with reversible lesion methods using a different spatial task has found remote memory to be spared. To determine whether the finding of spared remote spatial memory depends on the lesion method, we reversibly inactivated the hippocampus with lidocaine either immediately (O-DAY) or 1 mo (30-DAY) after training in a water maze. For both the O-DAY and 30-DAY retention tests, rats that received lidocaine infusions exhibited impaired performance. In addition, when the O-DAY group was retested $2 \mathrm{~d}$ later, (when the drug was no longer active), the effect was reversed. That is, rats that had previously received lidocaine performed as well as control rats did. These findings indicate that the rodent hippocampus is important for both recent and remote spatial memory, as assessed in the water maze. What determines whether remote spatial memory is preserved or impaired following disruption of hippocampal function appears to be the type of task used to assess spatial memory, not the method used to disrupt the hippocampus.
\end{abstract}

Bilateral damage to the hippocampal region (the CA fields, dentate gyrus, and subicular complex) in both humans and experimental animals results in retrograde amnesia, that is, loss of memories that were acquired before the onset of amnesia (Squire et al. 2001; Manns et al. 2003). Typically, retrograde amnesia is temporally graded such that remote memories are spared relative to memories that were acquired more recently. In the human, spared remote memory has also been demonstrated for knowledge of routes and locations learned early in life (Teng and Squire 1999). However, spared remote memory following lesions of the hippocampal region (referred to hereafter as the hippocampus) has yet to be observed in the rodent, when training is conducted in the water maze or in similar spatial tasks (Bolhuis et al. 1994; Mumby et al. 1999; Sutherland et al. 2001; Clark et al. 2005a,b; Martin et al. 2005). For example, we recently assessed spatial memory in rats by using the standard water maze task and two related tasks of spatial memory (a dry-land version of the water maze, the Oasis maze [Clark et al. 2005a], and the annular maze [Hollup et al. 2001]). In all three tasks, animals with large, bilateral hippocampal lesions were similarly impaired in tests of recent and remote memory, even after training-surgery intervals as long as $14 \mathrm{wk}$ (Clark et al. 2005a). In the standard water maze, impairment was also observed when rats were trained extensively for $69 \mathrm{~d}$ beginning early in life before receiving hippocampal lesions after a delay of $100 \mathrm{~d}$ (Clark et al. 2005b).

Recent studies with techniques to inactivate the hippocampus reversibly have yielded different results. Maviel and colleagues (2004) reported preserved remote spatial memory in mice following training in a radial maze. In that study, mice were trained to discriminate a single target arm from four alternative arms. Lidocaine infused into the dorsal hippocampus disrupted spatial memory for the trained arm when it was infused $1 \mathrm{~d}$ after training but not when it was infused 1 mo after training. Further,

\section{${ }^{5}$ Corresponding author.}

E-mail reclark@ucsd.edu; fax (858) 534-1569.

Article and publication are at http://www.learnmem.org/cgi/doi/10.1101/ Im.134706. imaging of the activity-dependent, immediate early gene Zif268 (Egr1) during retention testing revealed less induction of hippocampal Zif268 during the 1-mo test than during the 1-d test (Maviel et al. 2004). Both these findings are consistent with the idea that remote spatial memory in rodents is less dependent on the hippocampus than recent spatial memory.

It is unclear why remote spatial memory was preserved when hippocampal function was disrupted reversibly (Maviel et al. 2004) but impaired when hippocampal function was disrupted by permanent lesions (Mumby et al. 1999; Sutherland et al. 2001; Clark et al. 2005a,b; Martin et al. 2005). One possibility is that permanent hippocampal lesions have some chronic effect on brain circuitry (such as progressive damage to structures remote to the hippocampus) that does not occur following temporary, reversible inactivation (Lomber 1999). Another possibility is that tasks such as the water maze have unique characteristics that distinguish them from other spatial tasks such as the fivearm maze used by Maviel et al. (2004). If so, then reversible inactivation of the hippocampus by lidocaine might spare remote memory in the five-arm maze, as reported by Maviel et al. (2004), but not spare remote memory of the platform location in the water maze. To test these possibilities, we trained rats in the standard water maze, and then, either a few hours or 1-mo later, we gave a retention test after infusing lidocaine (or artificial cerebral spinal fluid [aCSF]) into the dorsal hippocampus.

\section{Results}

\section{Histology}

Figure 1 illustrates the tip location of the internal (injection) cannulae for each of the four experimental groups (0-DAY aCSF, $n=20$; 0-DAY lidocaine, $n=20$; 30-DAY aCSF, $n=19$; 30-DAY lidocaine, $n=19)$. The tips of the internal cannulae were consistently located within the dorsal hippocampus. All rats had damage to the cortex overlying the injection sites due to the placement of the guide cannula. 


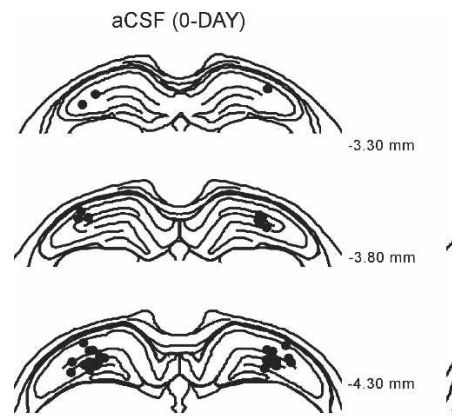

aCSF (30-DAY)
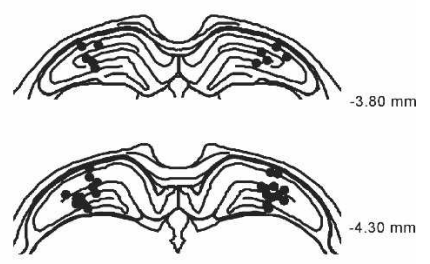

LIDOCAINE (0-DAY)
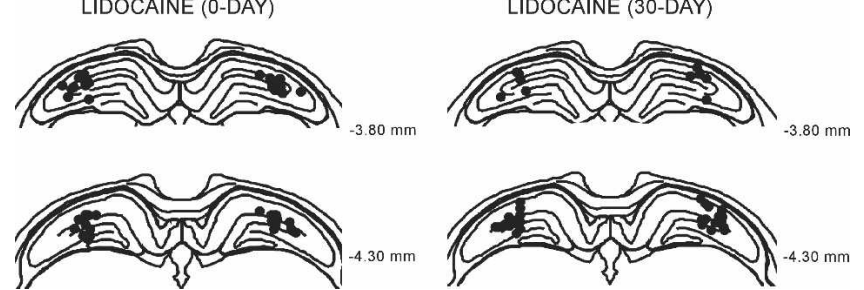

Figure 1. Schematic representation of injection sites in the dorsal hippocampus for each of the four groups (0-DAY aCSF, 0-DAY lidocaine, 30-DAY aCSF, 30-DAY lidocaine). Each black dot shows the injection site for a single cannula per animal.

\section{Acquisition}

Figure 2A shows acquisition of the hidden platform location by each group during the 10 daily training sessions. Memory for the platform location was measured by 60 -sec probe trials that were given at the beginning of each session. All groups learned the platform location to a similar degree (time in training quadrant during the final probe trial; 0 -DAY lidocaine, $58.3 \% \pm 4.1 \%$; 0 -DAY aCSF, $57.9 \% \pm 3.6 \%$; 30-DAY lidocaine, $55.5 \% \pm 3.2 \%$; 30 -DAY aCSF, $58.7 \% \pm 3.2 \%$ ). Each of these scores was well above the chance level of $25 \%$ ( $t s>8.0, P s<0.0001$ ). We also assessed learning by determining the percentage of time that animals spent in a small zone centered on the hidden platform location (diameter $=30 \mathrm{~cm}, 4.0 \%$ of the water surface). Average performance on the final probe trial for each of the four groups ranged from $17 \%$ to $18.7 \%$, and these scores were well above the chance value of $4 \%(t s>7.5$, Ps $<0.0001)$ and did not differ from each other $(t s<0.9, P s>0.5)$.

Figure $2 \mathrm{~B}$ shows the time taken to reach the hidden platform on each training day. All the groups learned to escape to the hidden platform at a similar rate during training. The latency to escape to the hidden platform on the final session of training was equivalent for the four groups ( 0 -DAY lidocaine, $6.0 \pm 0.5 \mathrm{sec}$; 0 -DAY aCSF, $5.5 \pm 0.2 \mathrm{sec}$; 30-DAY lidocaine, $5.2 \pm 0.2 \mathrm{sec}$; 30DAY aCSF, $7.1 \pm 1.0 \mathrm{sec} ; F_{[3,74]}=2.2, P=0.1$ ).
$P=0.8$ ). Planned comparisons revealed that the lidocaine group was impaired relative to the aCSF group at both retention intervals $(0-\mathrm{DAY}, 38.3 \% \pm 3.0 \%$ vs. $54.0 \% \pm 3.2 \%$; $30-\mathrm{DAY}$, $45.1 \% \pm 3.9 \%$ vs. $58.7 \% \pm 4.2 \%$; ts $>2.4$, Ps $<0.05$ ), although all groups spent more time in the training quadrant than would be expected by chance (chance $=25 \%$; $t s>4.5, P s<0.001$ ). Swim paths during the retention test for representative animals in each group are shown in Figure 3B.

We also assessed retention by determining the time spent by each group in the small training zone centered on the hidden platform ( $4 \%$ of total area). An ANOVA with retention interval (0-DAY vs. 30-DAY) and drug (lidocaine vs. aCSF) as factors revealed an effect of $\operatorname{drug}\left(F_{[1,74]}=14.7, P<0.001\right)$ and delay $\left(F_{[1,74]}=4.4, P<0.05\right)$, but no drug $\times$ delay interaction $\left(F_{[1,74]}=0.8, P=0.8\right)$. Planned comparisons revealed that the aCSF group spent more time than did the lidocaine group in the small training zone for the 0 -DAY test $(15.4 \% \pm 1.8 \%$ vs. $\left.6.4 \% \pm 1.5 \% ; t_{[38]}=3.8, P<0.001\right)$, and marginally more time in the small zone on the 30-DAY test than did the lidocaine group $\left(17.8 \% \pm 2.4 \%\right.$ vs. $\left.12.1 \% \pm 1.9 \% ; t_{[36]}=1.9, P=0.07\right)$. Furthermore, with the exception of the 0 -DAY lidocaine group $(t=1.6, P=0.1)$, the 0 -DAY and 30-DAY aCSF groups and the 30-DAY lidocaine group spent more time in the training zone than would be expected by chance (chance $=4 \%$; $t s>4.2$, $P s<0.001)$.

Finally, we calculated the number of times each animal entered the small target zone during the 1-min probe trial. Animals in the 30-DAY lidocaine group averaged $4.9 \pm 0.5$ entries into the small target zone, and animals in the 30-DAY aCSF group averaged $7.7 \pm 0.8$ entries into the small target zone $\left(t_{[36]}=2.9\right.$, $P<0.01)$. The same pattern was found with the 0-DAY groups (0-DAY aCSF, $6.5 \pm 0.6$; 0 -DAY lidocaine, $3.6 \pm 0.7 ; t_{[38]}=3.21$, $P<0.01)$.

\section{Retest}

Two days after the 0-DAY retention test, the lidocaine and aCSF groups were retested by giving a single reinforced probe trial (Fig. 4). The lidocaine group and the aCSF group performed similarly (time in the training quadrant $=52.5 \% \pm 5.3 \%$ vs. $\left.56.0 \% \pm 3.2 \% ; t_{[38]}=0.6, P=0.6\right)$. Furthermore, the performance of the aCSF group at the 0 -DAY test and at retest was similar $(54.0 \%$ vs. $56.0 \% ; t=0.6, P=0.6)$, despite the fact that at retest there was no vehicle infusion. Thus, the infusion procedure did not affect performance. In contrast to the aCSF group, the performance of the lidocaine group was better than when testing occurred just after drug infusion $(52.5 \% \pm 5.3 \%$ vs. $\left.38.3 \% \pm 3.0 \%, t_{[19]}=2.1, P<0.05\right)$. Swim paths for representative animals in each group are shown in Figure 4B.

The findings were identical when performance was assessed by the time spent in the small training zone (lidocaine retest, $17.1 \% \pm 2.6 \%$ vs. aCSF retest, $16.6 \% \pm 1.7 \%, t_{[38]}=0.2, P>0.8$

\section{Spatial memory retention}

The percentage of time spent in the training quadrant on the 0 -DAY and 30DAY retention tests is shown in Figure 3A. An ANOVA with retention interval (0-DAY vs. 30-DAY) and drug (lidocaine vs. aCSF) as factors revealed that the lidocaine group spent less time in the training quadrant than did the aCSF group $\left(F_{[1,74]}=16.7, P<0.0001\right)$. There was no effect of retention interval $\left(F_{[1,74]}=2.6, P=0.1\right)$ and no retention interval $\times$ drug interaction $\left(F_{[1,74]}=0.91\right.$,
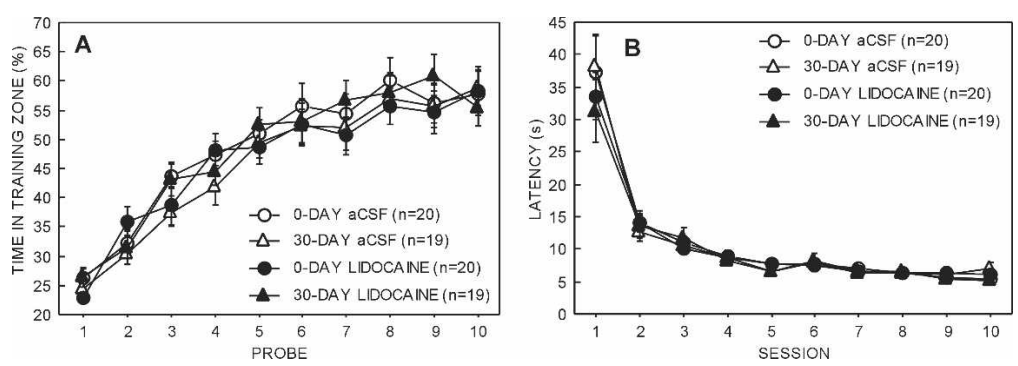

Figure 2. Acquisition of spatial memory in the water maze. $(A)$ Percentage of time spent in the training quadrant on each of ten $60-\mathrm{sec}$ daily probe trials. Chance $=25 \%$. (B) Average latency to escape to the hidden platform on each of the 10 daily training sessions. Parentheses show SEM.

\section{Learning \& Memory}



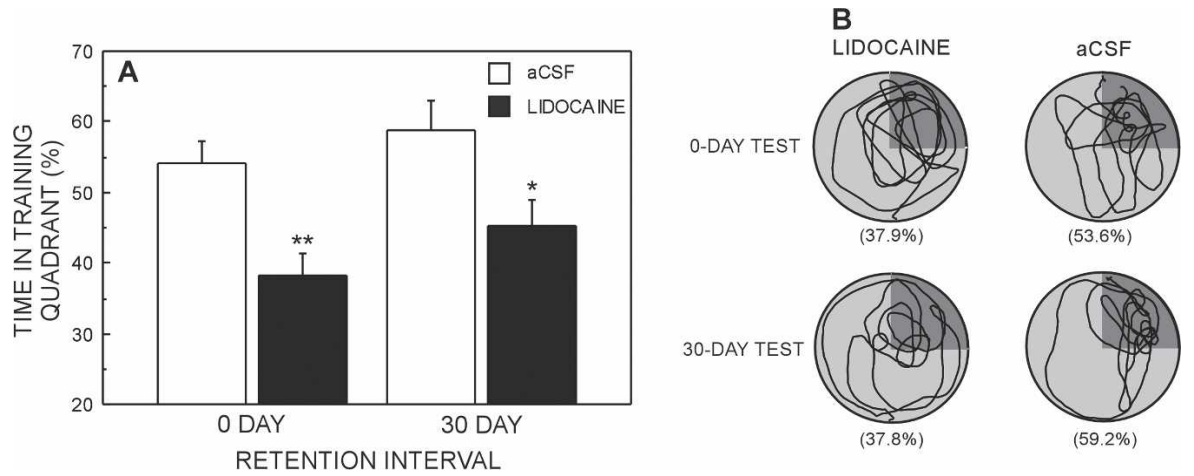

Figure 3. (A) Performance of the aCSF and lidocaine groups on probe trials given 0 or $30 \mathrm{~d}$ after the completion of training. Chance $=25 \%$. Parentheses show SEM. Asterisks denote that the lidocaine group was different from the aCSF group $\left.{ }^{* *} p<0.01,{ }^{*} P<0.05\right)$. (B) Swim paths for representative animals that received either lidocaine or aCSF infusions prior to the 0-DAY or 30-DAY retention tests. The training quadrant appears in dark gray. Percentages in parentheses refer to the percentage of time spent in the training quadrant.

aCSF retest, $16.6 \% \pm 1.7 \%$ vs. 0 -DAY aCSF, $15.4 \% \pm 1.8 \%$; $t_{[19]}=0.6, P>0.5$; lidocaine retest, $17.1 \% \pm 2.6 \%$ vs. 0 -DAY lidocaine, $\left.6.4 \% \pm 1.5 \% ; t_{[19]}>3.2, P<0.01\right)$. Thus, the performance of the lidocaine group returned to normal levels once the drug was no longer active. Lidocaine infusion did not permanently disrupt spatial memory but temporarily impaired its expression.

\section{Discussion}

Inactivation of the hippocampus with lidocaine either $4-5 \mathrm{~h}$ or 1 $\mathrm{m}$ after training impaired memory of a previously learned platform location in the water maze. Further, memory returned to control levels when the 0-DAY retention group was retested after the effects of the lidocaine had dissipated. These findings suggest that temporary inactivation of the hippocampus did not permanently disrupt spatial memory but rather prevented its expression. Impaired memory has also been reported in the water maze following infusion of an AMPA/Kainate receptor antagonist (a CNQX analog) into the dorsal hippocampus (Riedel et al. 1999; Micheau et al. 2004). In those studies, hippocampal function was briefly inactivated during a single, 60 -sec probe test conducted 16 $d$ after the completion of training. Our study extends these findings by showing that hippocampal inactivation also impairs the retention of spatial memory in the water maze when the training-inactivation interval is extended to as long as $30 \mathrm{~d}$.

Taken together, the available data indicate that reversible disruption of hippocampal function by lidocaine, or by a CNQX analog, impairs remote spatial memory in the water maze (Riedel et al. 1999; Micheau et al. 2004; the present study). In contrast, disruption of hippocampal function by lidocaine does not disrupt remote memory in a spatial discrimination task (Maviel et al. 2004). Because both we and Maviel et al. (2004) used lidocaine to test spatial memory at 1 mo after learning, neither the method used to disrupt hippocampal function nor the training-inactivation interval can account for the contrasting results. Accordingly, we considered the possible importance of the kind of spatial memory task used in these and other studies.
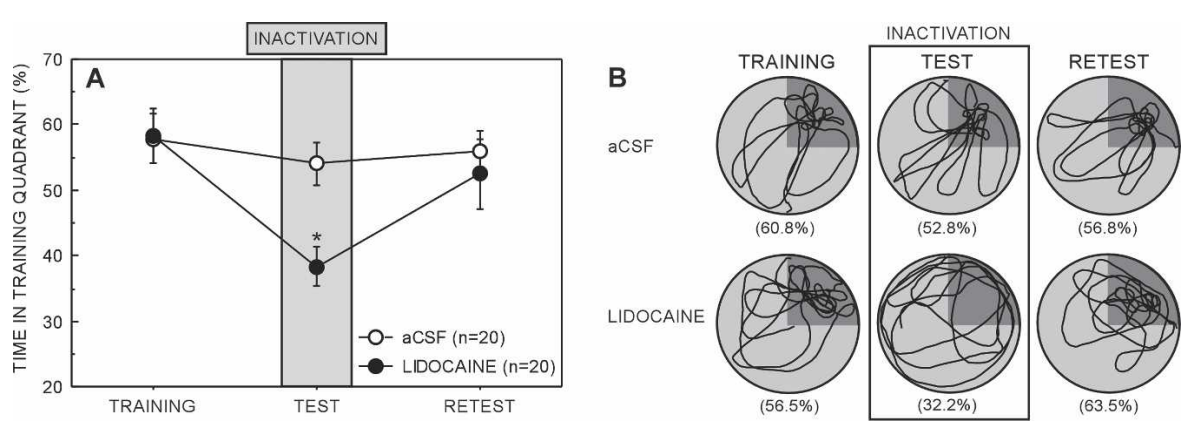

Figure 4. (A) Spatial memory performance of the 0-DAY aCSF and lidocaine groups on the final probe trial of training (training), on the probe test $5 \mathrm{~min}$ after drug infusion (test), and on the probe trial given $2 \mathrm{~d}$ later (retest). The gray bar indicates the time that the drug was active. Chance $=25 \%$. Parentheses show SEM. Asterisk denotes impairment relative to the aCSF group $(P<0.05)$. (B) Swim paths during training, during the test, and during the retest for representative animals that received lidocaine or aCSF infusions 5 min prior to the 0-DAY retention tests. The training quadrant appears in dark gray. Percentages in parentheses refer to the percentage of time spent in the training quadrant. 
memory due to the performance requirements of the test. Note, for example, that the severely amnesic patient E.P. could describe in considerable detail how to navigate the neighborhood in which he grew up (Teng and Squire 1999). However, one would not expect him to be able to do as well if he were asked to express his knowledge by walking through his town. Due to the time constraints of physically traveling compared with mentally traveling, he would continually forget where he is and where he had just been.

The present findings demonstrate that impaired remote spatial memory in the water maze following disruption of hippocampal function is not peculiar to studies using permanent hippocampal lesions. Impaired remote spatial memory is also observed when hippocampal function is reversibly disrupted. The critical variable determining whether remote spatial memory is preserved or impaired following disruption of hippocampal function appears to be the type of task used to assess spatial memory. Accordingly, it is premature to confer special status on spatial memory in discussions of rodent hippocampal function.

\section{Materials and Methods}

\section{Subjects}

The subjects were 78 male, Long-Evans rats weighing 300-350g at the beginning of the study. Rats were housed individually and maintained on a 12-h light/12-h dark cycle. Food and water were available ad libitum. Prior to training, rats were implanted with guide cannulae in the dorsal hippocampus.

\section{Surgery and histology}

Anesthesia was maintained throughout surgery with isoflurane gas $\left(0.8 \%-2.0 \%\right.$ isoflurane delivered in $\mathrm{O}_{2}$ at $\left.1 \mathrm{~L} / \mathrm{min}\right)$. The rat was placed in a stereotaxic instrument (Kopf Instruments), and the incisor bar was adjusted until bregma was level with lambda. Sterile 22-gauge, stainless steel guide cannulae (Plastics One Inc.) were implanted bilaterally into the dorsal hippocampus (millimeters from bregma, $\mathrm{AP}=-4.3, \mathrm{ML}= \pm 3.5, \mathrm{DV}=-2.0)$ (Paxinos and Watson 1998). Anchoring screws and dental acrylic secured the guide cannula to the skull. The skin was approximated around the implant and sutured in place. At completion of surgery, a dummy cannula (Plastics One Inc.) was inserted into each guide cannula to maintain patency. Each rat received Baytril (Bayer Corporation) antibiotic for prophylaxis against infection $(0.1 \mathrm{~mL}$ subcutaneously for $2 \mathrm{~d}$ ). All rats were given at least 7-d recovery before water maze training began.

At completion of testing, the rats were administered an overdose of sodium pentobarbital and perfused transcardially with buffered $0.9 \% \mathrm{NaCl}$ solution followed by $10 \%$ formaldehyde solution (in $0.1 \mathrm{M}$ phosphate buffer). The brains were then removed and cryoprotected in $20 \%$ glycerol/10\% formaldehyde. Coronal sections $(50 \mu \mathrm{m})$ were cut with a freezing microtome beginning at the level of the anterior commissure and continuing caudally through the length of the hippocampus. Every fifth section was mounted and stained with thionin to verify the cannula placements within the dorsal hippocampus.

\section{Infusion protocol}

Prior to the infusion, each dummy cannula was removed, and 28-gauge internal cannulae were inserted until the tips extended $1.5 \mathrm{~mm}$ beyond the end of the guide cannulae at a depth of 3.5 $\mathrm{mm}$ below the level of bregma. Two microliters of either aCSF (Harvard Apparatus) or 4\% lidocaine hydrochloride solution (in aCSF; Sigma-Aldrich) was then delivered at a rate of $1 \mu \mathrm{L} / \mathrm{min}$ by a dual syringe pump (Model 11 plus; Harvard Apparatus). The spread of lidocaine inactivation has been well characterized and can be estimated with an established formula based on injection volume (Tehovnik and Sommer 1997). A 2- $\mu \mathrm{L}$ injection of lidocaine will produce a spherical area of inactivation of $2.0 \mathrm{~mm}$ emanating from the cannulae tips. At the completion of infu- sion, the internal cannulae were left in place for $60 \mathrm{sec}$. Testing began $5 \mathrm{~min}$ after removal of the internal cannula.

\section{Apparatus}

Testing was conducted in the Morris water maze (diameter, 1.8 $\mathrm{m})$ with an "Atlantis Platform" (diameter $=12.7 \mathrm{~cm})($ Spooner et al. 1994), which could be raised or lowered remotely. The platform was located in the center of the northeast quadrant of the pool throughout spatial testing. The water was rendered opaque by the addition of powdered milk, and the room was illuminated by four $30-\mathrm{W}$ spotlights pointed at a white ceiling. The water was maintained at room temperature $\left(23^{\circ} \mathrm{C}\right)$. The testing room contained a number of constant, salient visual cues (posters, objects, and equipment), and an opaque curtain shielded the experimenter from the rat once a trial began. A video camera was mounted on the ceiling directly above the pool and was used, in conjunction with a video tracking system (San Diego Instruments), to record the swim path of each rat.

\section{Procedure}

\section{Spatial training}

Rats received one training session each day for $10 \mathrm{~d}$. Each daily session began with a single reinforced probe trial, followed by four training trials. For the probe trials, the platform was lowered so that it was inaccessible, and the rat was placed in the water facing the pool wall at one of four start points (north, south, east, or west). The start points were counterbalanced across trials for all animals. Upon release into the water, the rat was allowed to swim for $60 \mathrm{sec}$, at which point the platform was raised to within $1.5 \mathrm{~cm}$ of the water surface. An additional $60 \mathrm{sec}$ were then allowed for the rat to locate the platform and escape from the water. After escaping, the rat remained on the platform for $30 \mathrm{sec}$ before being removed. If the rat failed to escape, it was guided to the platform and remained there for $30 \mathrm{sec}$

After completion of the daily probe trial, four training trials were given with the platform in the raised position $(1.5 \mathrm{~cm}$ below the water surface) so that it provided a means of escape from the water. The procedure was the same as for the probe trials, except that the rat was allowed $120 \mathrm{sec}$ to find the platform. Prior to training sessions $2,4,7$, and 9 , sham infusions were given in order to acclimate rats to the infusion procedure. The sham infusion procedure was identical to that used on the test day with the exception that no drug or vehicle was delivered. On completion of training, rats were assigned to an immediate retention test group (0-DAY) or a delayed retention test group (30-DAY), and also to a drug condition (aCSF or lidocaine) such that the average percentage of time spent in the training quadrant on sessions 9 and 10 was equivalent for all four groups.

\section{Immediate $(0-D A Y)$ retention test}

Four to five hours after the completion of the final training session, rats were infused with either $4 \%$ lidocaine $(n=20)$ or with aCSF $(n=20)$ and were given a single, 60 -sec reinforced probe trial. Two days after the test, rats were given another 60 -sec reinforced probe trial but no drug or vehicle was infused.

\section{Remote (30-DAY) retention test}

On completion of training, rats were returned to the colony for a 30 -d interval. Twice a week during the delay period, sham infusions were given to acclimate rats to the handling and infusion procedure. At the end of the 30-d delay, rats were infused with $4 \%$ lidocaine $(n=19)$ or aCSF $(n=19)$ and then given a single, 60 -sec reinforced probe trial.

\section{Acknowledgments}

This work was supported by the Medical Research Service of the Department of Veterans Affairs, the National Institute of Mental Health, the Metropolitan Life Foundation, the National Science Foundation, the James S. McDonnell Foundation, and a 2002 National Alliance for Research on Schizophrenia and Depression 
Effie Beeman Investigator Award (N.J.B.). We thank Laura Entwistle and Daniel Guadarrama for assistance.

\section{References}

Bolhuis, J.J., Stewart, C.A., and Forrest, E.M. 1994. Retrograde amnesia and memory reactivation in rats with ibotenate lesions to the hippocampus and subiculum. Q. J. Exp. Psychol. 47B: 129-150.

Cho, Y.H. and Kesner, R.P. 1996. Involvement of entorhinal cortex or parietal cortex in long-term spatial discrimination memory in rats: Retrograde amnesia. Behav. Neurosci. 110: 436-442.

Cho, Y.H., Beracochea, D., and Jaffard, R. 1993. Extended temporal gradient for the retrograde and anterograde amnesia produced by ibotenate entorhinal cortex lesions in mice. J. Neurosci. 13: $1759-1766$.

Clark, R.E., Broadbent, N.J., and Squire, L.R. 2005a. Hippocampus and remote spatial memory in rats. Hippocampus 15: 260-272.

_. 2005b. Impaired remote spatial memory after hippocampal lesions despite extensive training beginning early in life. Hippocampus 15: 340-346.

Hollup, S.A., Kjelstrup, K.G., Hoff, J., Moser, M.B., and Moser, E. 2001. Impaired recognition of the goal location during spatial navigation in rats with hippocampal lesions. J. Neurosci. 12: 4505-4513.

Knowlton, B.J. and Fanselow, M.S. 1998. The hippocampus, consolidation and on-line memory. Curr. Opin. Neurobiol. 8: $293-296$.

Kubie, J.L., Sutherland, R.J., and Muller, R.U. 1999. Hippocampal lesions produce a temporally graded retrograde amnesia on a dry version of the Morris swimming task. Psychobiology 27: 313-330.

Lomber, S.G. 1999. The advantages and limitations of permanent or reversible deactivation techniques in the assessment of neural function. I. Neurosci. Methods 86: 109-117.

Manns, J.R., Hopkins, R.O., Reed, J.M., Kitchener, E.G., and Squire, L.R. 2003. Recognition memory and the human hippocampus. Neuron 37: 1-20.

Martin, S.J., de Hoz, L., and Morris, R.G.M. 2005. Retrograde amnesia: Neither partial nor complete hippocampal lesions in rats result in preferential sparing of remote spatial memory even after reminding. Neuropsychologia 43: 609-624.

Maviel, T., Durkin, T.P., Menzaghi, F., and Bontempi, B. 2004. Sites of neocortical reorganization critical for remote spatial memory. Science 305: 96-99.

Micheau, J., Riedel, G., Roloff, E.V.L., Inglis, J., and Morris, R.G.M. 2004. Reversible hippocampal inactivation partially dissociates how and where to search in the water maze. Behav. Neurosci. 118: 1022-1032.

Mumby, D.G., Astur, R.S., Weisend, M.P., and Sutherland, R.J. 1999. Retrograde amnesia and selective damage to the hippocampal formation: Memory for places and object discriminations. Behav. Brain Res. 106: 97-107.

Paxinos, G. and Watson, C. 1998. The rat brain in stereotaxic coordinates. Elsevier Academic Press, Amsterdam.

Ramos, J. 1998. Retrograde amnesia for spatial information: Dissociation between intra and extramaze cues following hippocampus lesions in rats. Eur. J. Neurosci. 10: 3295-3301.

Riedel, G., Micheau, J., Lam, A.G., Roloff, E., Martin, S.J., Bridge, H., de Hoz, L., Poeschel, B., McCulloch, J., and Morris, R.G.M. 1999. Reversible neural inactivation reveals hippocampal participation in several memory processes. Nat. Neurosci. 2: 898-905.

Spooner, R.I.W., Thomson, A., Hall, J., Morris, R.G.M., and Salter, S.H. 1994. The Atlantis platform: A new design and further developments of Buresova's on-demand platform for the water maze. Learn. Mem. 3: $203-211$.

Squire, L.R., Clark, R.E., and Knowlton, B.J. 2001. Retrograde amnesia. Hippocampus 11: 50-55.

Sutherland, R.J., Weisend, M.P., Mumby, D., Astur, R.S., Hanlon, F.M., Koerner, A., Thomas, M.J., Wu, Y., Moses, S.N., Cole, C., et al. 2001. Retrograde amnesia after hippocampal damage: Recent vs. remote memories in three tasks. Hippocampus 11: $27-42$.

Tehovnik, E.J. and Sommer, M.A. 1997. Effective spread and time course of neural inactivation caused by lidocaine injection in monkey cerebral cortex. J. Neurosci. Methods 74: 17-26.

Teng, E. and Squire, L.R. 1999. Memory for places learned long ago is intact after hippocampal damage. Nature 400: 675-677.

Received November 8, 2005; accepted in revised form January 12, 2006. 


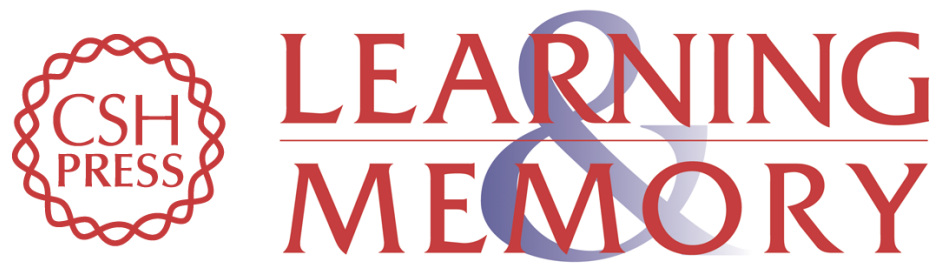

\section{Reversible hippocampal lesions disrupt water maze performance during both recent and remote memory tests}

Nicola J. Broadbent, Larry R. Squire and Robert E. Clark

Learn. Mem. 2006, 13:

Access the most recent version at doi:10.1101//m.134706

References This article cites 19 articles, 2 of which can be accessed free at:

http://learnmem.cshlp.org/content/13/2/187.full.html\#ref-list-1

License

Email Alerting Receive free email alerts when new articles cite this article - sign up in the box at the Service top right corner of the article or click here. 